\title{
Enzyme-Activated Surfactants for Dispersion of Carbon Nanotubes**
}

\author{
Brian G. Cousins, Apurba K. Das, Raman Sharma, Yanning Li, Jonathan \\ P. McNamara, Ian H. Hillier, * Ian A. Kinloch, * and Rein V. Ulijn*
}

The processing of carbon nanotubes (CNTs) remains a significant barrier in the exploitation of their unique properties. $^{[1]}$ CNT dispersions have been achieved by noncovalent modification using surfactants and polymers with aromatic functionalities that assemble onto nanotube surfaces via $\pi-\pi$ interactions. ${ }^{[2,3]}$ Synthetic aromatic ligands, such as pyrene and its derivatives, have also been used as low-cost surfactants for simultaneous CNT dispersion and functionalization. ${ }^{\text {[4-7] }}$ For systems where an interface between CNTs and biological systems is required (e.g., biosensing) biological macromolecules containing aromatic residues such as polysaccharides, DNA, RNA, and peptides have been studied. ${ }^{[8-9]}$ Peptides are especially attractive in this context because of their rich, adaptable chemistry and the possibility of identifying CNT binding peptide sequences using massive combinatorial libraries by exploiting phage display. ${ }^{[10-11]}$ These sequences usually contain 12 or more residues and are invariably rich in aromatic amino acids such as tryptophan (W) and histidine (H). Combining these aromatic amino acids with synthetic aromatic ligands may provide surfactants that combine biology's versatility with the robustness and cost-effectiveness

[*] Prof. I. H. Hillier, Dr. R. Sharma, Dr. J. P. McNamara

School of Chemistry

University of Manchester

Oxford Road, Manchester, M13 9PL (UK)

E-mail: Ian.Hillier@manchester.ac.uk

Dr. I. A. Kinloch, Dr. B. G. Cousins, Y. Li

School of Materials, Materials Science Centre

University of Manchester

Grosvenor Street, Manchester, M1 7HS (UK)

E-mail: Ian.Kinloch@manchester.ac.uk

Prof. R. V. Ulijn, ${ }^{[+]}$Dr. A. K. Das ${ }^{[+]}$

Manchester Interdisciplinary Biocentre (MIB) and

School of Materials

University of Manchester

Grosvenor Street, Manchester, M1 7HS (UK)

E-mail: Rein.Ulijn@strath.ac.uk

[+] Present address: WestCHEM, University of Strathclyde, Thomas Graham Building, 295 Cathedral Street, Glasgow G1 1XL, UK

[**] This work was supported by the Engineering and Physical Sciences Research Council (EPSRC award No. EP/D07410X/1) and the Royal Academy of Engineering. We thank Polly Crook for technical assistance and Robin Hadley for digital photography.

品 Supporting Information is available on the WWW under http:// www.small-journal.com or from the author.

DOI: $10.1002 / \mathrm{smll} .200801184$ of synthetic systems. N-(Fluorenyl-9-methoxycarbonyl) (Fmoc) was selected as a particularly promising ligand since it is used commonly as a protecting group in solid-state peptide synthesis, that is, Fmoc-peptides are intermediates in synthetic peptide systems and may be used directly for CNT immobilization. Furthermore, it is known that Fmoc amino acids can interact via $\pi-\pi$ interactions, as such molecules can self-assemble into nanostructures. $^{[12-13]}$ As a second aim, we studied whether Fmoc-peptide-based surfactants could be converted into enzymatically addressable systems ${ }^{[14-16]}$ that might be used to assemble, disperse, or stabilize CNTs on-demand under constant conditions of $\mathrm{pH}$, ionic strength, and temperature.

Four Fmoc-protected aromatic amino acids, W, H, tyrosine (Y), and phenylalanine (F), were selected, with glycine (G) as a nonaromatic control (Figure 1a). The interactions of these molecules with single- and multiwalled nanotubes (SWNTs and MWNTs) were studied by examining their ability to disperse CNTs in phosphate buffer saline (PBS). The degree of dispersion was then assessed using UV-Vis spectroscopy (see Supporting Information). The SWNTs were provided by Thomas Swan \& Co. Ltd, U.K. (Elicarb ${ }^{\circledR}$ ) and the MWNTs were manufactured in-house by chemical vapor deposition (CVD) using previous published protocols. ${ }^{[17]}$ The physical aggregates of SWNTs were broken up manually using tweezers before dispersion, whereas the MWNTs were grown as aligned arrays and therefore did not require any mechanical pretreatment. The characterization and dimensions of CNTs are discussed in the supporting information.

The dispersions were prepared with each vial containing CNTs (1 mg) to which a solution of amino acid derivatives ( $3 \mathrm{~mL}, 0.6 \mathrm{~mm}$ ) was added. The mixture was then ultrasonicated using a microprobe and a low power bath for $4 \mathrm{~min}$. Two minutes of sonication increased the local temperature of the samples by $10{ }^{\circ} \mathrm{C}$ and the low-power water bath was used at room temperature for a further $2 \mathrm{~min}$. The degree of dispersion was assessed by the turbidity from which the concentration of nanotubes was calculated using Beer's law (see Supporting Information). The turbidity was obtained by measuring the absorption at $550 \mathrm{~nm}\left(A_{550 \mathrm{~nm}}\right)$ and $700 \mathrm{~nm}\left(A_{700 \mathrm{~nm}}\right)$ on aliquots taken from the dispersions and diluted ten-fold. The highest level of dispersions was obtained using Fmoc-W as the surfactant with concentrations of $0.08 \pm 0.01 \mathrm{mg} \mathrm{mL}^{-1}$ for SWNTs and $0.21 \pm 0.01 \mathrm{mg} \mathrm{mL}^{-1}$ for MWNTs (Figure 1b). These values are similar to those achieved by using the common surfactant sodium dodecyl sulfate (SDS), which dispersed $0.07 \pm 0.01 \mathrm{mg} \mathrm{mL}^{-1}$ of SWNTs and $0.20 \pm 0.03 \mathrm{mg} \mathrm{mL}^{-1}$ of 


\section{communications}

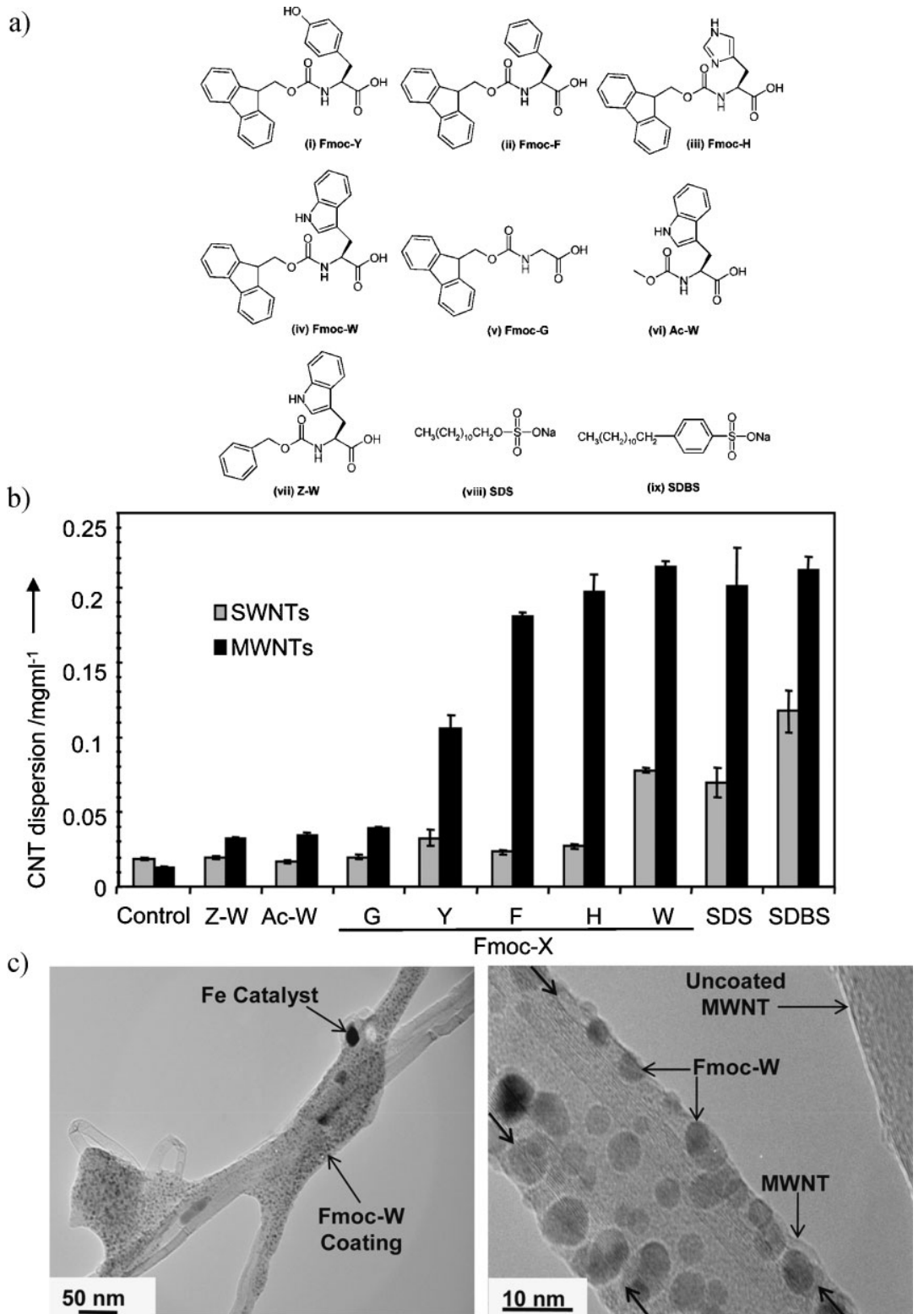

Figure 1. a) Molecular structures of aromatic amino acid derivatives and control surfactants. b) Turbidity measurements ( $\mathrm{mg} \mathrm{mL}^{-1}$ ) of SWNTs and MWNTs dispersed with Fmoc-, Ac-, and Z-protected amino acids, SDS and SDBS. The data were obtained $30 \mathrm{~min}$ after sonication. c) TEM micrographs of MWNTs dispersed with $0.6 \mathrm{~mm}$ Fmoc-W. Arrows indicate the edge of the lattice structure upon which Fmoc-W aggregates are apparent. as confirmed by quantum mechanical modeling as described further down.

Transmission electron microscopy (TEM) was used to examine morphological changes to the MWNT surface in the presence of Fmoc-W. Surface coverage was estimated from cross-sectional measurements from random TEM images ( $n=25, n$ is the number of cross-sectional lines (5) taken from five separate images). A heterogeneous coating was apparent, which ranged from 0 to $120 \mathrm{~nm}$ (Figure 1c). Highresolution images revealed spherical features, thought to be Fmoc-W aggregates, ranging from 5 to $10 \mathrm{~nm}$ in diameter.

Having demonstrated experimentally that Fmoc-W is a suitable surfactant for CNTs, we moved on to confirm molecular interactions between the ligand and nanotube surface using quantum mechanical modeling. The problem of accurately modeling $\pi-\pi$-stacking interactions, which are dominated by strong dispersive interactions, has received much attention recently. ${ }^{[18]} \mathrm{A}$ computationally effective strategy has been found to augment standard quantum mechanical methods, particularly density functional theory (DFT) and semi-empirical molecular orbital methods such as PM3, with an empirical $\left(\mathrm{R}^{-6}\right)$ term to account for the atom-atom dispersive interactions. We have shown that when modified in this way, the PM3 method (PM3-D) allows a large range of intermolecular interactions, including $\pi$ $\pi$-stacking, to be modeled accurately. ${ }^{[19]}$ This method has recently been shown to successfully model the interaction of a range of substrates with SWNTs. ${ }^{[20]}$ Herein we compute the interaction energies of Fmoc-G, Fmoc-Y, and Fmoc-W with the extended $\pi$ system of a CNT modeled by a $\approx 30 \AA$ length of a [6,6] SWNT. Figure 2 shows optimized structures following energy minimization. The aromatic fluorenyl rings were found to stack on the surface of the CNT to maximize
MWNTs. The aromatic surfactant sodium dodecylbenzyl sulfate (SDBS) performed better and dispersed $0.12 \pm 0.01 \mathrm{mg} \mathrm{mL}^{-1}$ of SWNTs and $0.21 \pm 0.01 \mathrm{mg} \mathrm{mL}^{-1}$ of MWNTs. The concentration of MWNTs dispersed was higher than that of the SWNTs for all the surfactants used, which is related to the latter being highly entangled due to their manufacturing process. The settling behavior of the CNT/ Fmoc-amino acid dispersions revealed a half-life of 3 days (see Supporting Information). Having established that Fmoc-W was the most effective dispersant, Fmoc was compared with other ligands - benzyloxycarbonyl ( $\mathrm{Z}$ ) and a nonaromatic acetyl (Ac) with Fmoc-W providing the highest dispersion (Figure $1 b$ ) - highlighting the role of $\pi$-stacking interactions

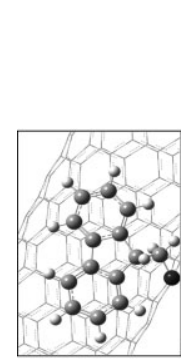

Fluorenyl
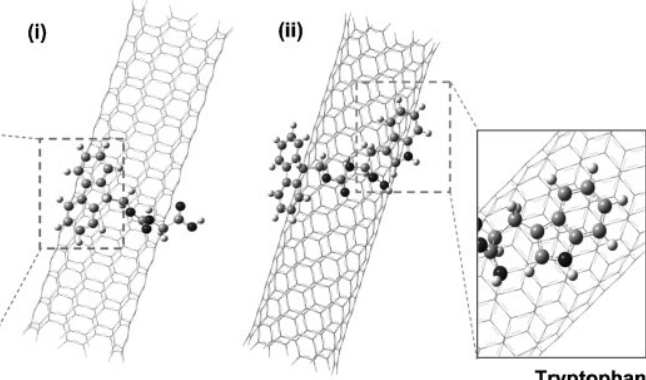

Tryptophan

Figure 2. Optimized structures of (i) Fmoc-G and (ii) Fmoc-W bound to $[6,6]$ SWNTs with close-up images that highlight the orientation and arrangement of Fmoc and the aromatic $W$ ring. 
their $\pi$-stacking interactions. ${ }^{[21]}$ The distance between the center of mass of the aromatic rings in Fmoc-W and the most proximal nanotube ring was approximately $3.5 \AA$, which is similar to the spacing $(002)$ found in graphite $(\approx 3.35 \AA)$. The CNT surface is hydrophobic and when Fmoc amino acids bind to the surface, polar groups $(-\mathrm{OH}$ and $-\mathrm{COOH})$ on the amide backbone give rise to surfactant-like properties. ${ }^{[22]}$ Additional interactions also occur between surface-bound and non-bound Fmoc amino acids via $\pi$-stacking and hydrogen bonding, which might contribute to the overall formation of a stable dispersion of nanotubes in aqueous media. However, in this work we have focused on the primary interactions between the Fmoc derivatives and the CNTs.

The substrate interaction energy in the Fmoc-W and FmocY complexes with SWNTs was found to be greater by approximately 15 and $11 \mathrm{kcal} \mathrm{mol}^{-1}$ respectively than in the corresponding Fmoc-G/SWNT complex when the -COOH group is in the neutral state (Table 1). Calculations were carried out for both the neutral and charged amino acid states. The respective interaction energies when the $-\mathrm{COOH}$ group is
Table 1. Energetics ( $\mathrm{kcal} \mathrm{mol}^{-1}$ ) of the interaction of neutral and charged Fmoc amino acid substrates with $[6,6]$ SWNTs. At high $\mathrm{pH}$, $-\mathrm{COOH}$ is ionized on the surface, and values are given in parentheses.

\begin{tabular}{lccc}
\hline & Fmoc-G & Fmoc-Y & Fmoc-W \\
\hline Interaction energy & $-32.7(-36.2)$ & $-44.1(-43.8)$ & $-47.4(-47.7)$ \\
Strain energy & 0.9 & 3.6 & 7.4 \\
Contribution to & & & \\
interaction energy ${ }^{[a]}$ & & & \\
Fluorenyl ring & -20.7 & -20.4 & -20.0 \\
W or Y ring & - & -10.8 & -14.3 \\
Backbone & -12.8 & -14.7 & -14.9 \\
\hline
\end{tabular}

[a] The sum of the individual contributions differs slightly from the total value since hydrogen atoms had to be added to the fragments to satisfy the valency of Fmoc amino acids interacting with CNTs.

ionized, corresponding to high $\mathrm{pH}$, are not significantly different from the values for unionized-COOH. We may define the strain energy of the substrate as the energy penalty incurred when the substrate changes from it's in vacuo geometry to that in the complex. The difference in the strain energy for Fmoc-W

a)<smiles>CON(C)[C@H](C)C(=O)N[C@@H](Cc1c[nH]c2ccccc12)C(=O)N[C@@H](C)C(=O)OCC1c2ccccc2-c2ccccc21</smiles>

(i)

(ii)

(iii)<smiles>c1ccccc1</smiles><smiles>CC(=O)[C@H](N)[C@H](O)C(=O)O</smiles><smiles>O=C(N[C@H](Cc1c[nH]c2ccccc12)C(=O)O)OCC1c2ccccc2-c2ccccc21</smiles>
(Active)

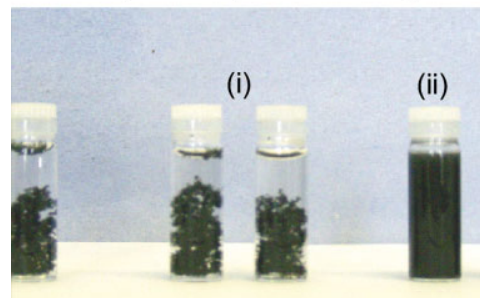

(iii) 0

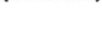

$\mathrm{R}_{1}=\mathrm{CH}_{2} \mathrm{CH}\left(\mathrm{CH}_{3}\right)_{2}-$ Leu

$=\mathrm{H}-\mathrm{Gly}$

$=$ Chymotrypsin or

Thermolysin

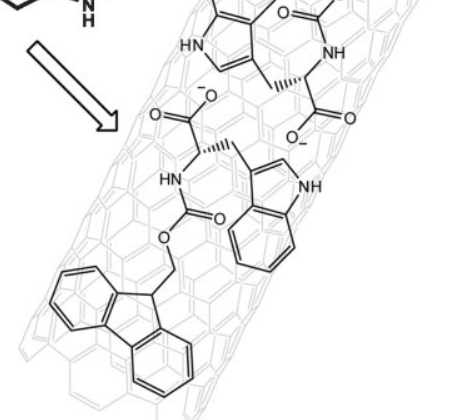

b)

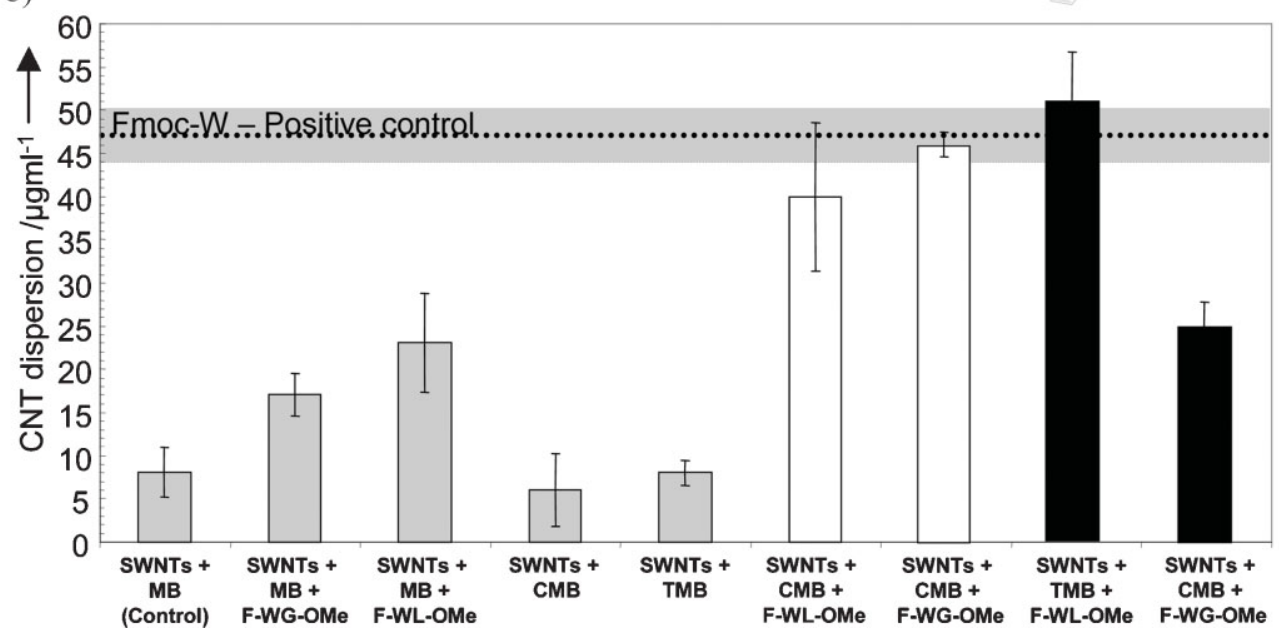

Figure 3. a) Schematic representation of enzyme-activated CNT dispersions. Optical image showing enzyme activation of CNTs dispersed with $0.6 \mathrm{~mm}$ Fmoc-W-L-OMe (i) and Fmoc-W-L-OMe with $100 \mu \mathrm{g} \mathrm{mL}^{-1}$ of (ii) chymotrypsin or (iii) thermolysin. b) Amount of dispersed SWNTs ( $\mu \mathrm{g} \mathrm{mL}^{-1}$ ) after centrifugation to remove control MBs. Immobilized enzymes were used to activate nanotube dispersions. The dashed line represents the positive control and level of dispersion produced by Fmoc-W $\left(\approx 47 \pm 2.8 \mu \mathrm{g} \mathrm{mL}^{-1}\right)$. The data were taken 30 min after sonication. 
$\left(7.4 \mathrm{kcal} \mathrm{mol}^{-1}\right)$, Fmoc-Y $\left(3.6 \mathrm{kcal} \mathrm{mol}^{-1}\right)$, and Fmoc-G $\left(0.9 \mathrm{kcal} \mathrm{mol}^{-1}\right)$, arises from the greater distortion of the backbone of the more strongly bound $\mathrm{W}$ and $\mathrm{Y}$ substrate in achieving optimal $\pi$-stacking with the surface. Table 1 gives the contribution to the overall interaction energy of the individual groups, namely the fluorenyl ring, W-ring, and amide backbone. It is found that for all three substrates the fluorenyl and amide backbone contributions are essentially the same, with the greater interaction of Fmoc-W and Fmoc-Y being due entirely to the aromatic rings.

Fmoc-W acts as an electrostatic surfactant, with titration experiments showing that the CNT dispersions are only stable above $\mathrm{pH}$ 4. These electrostatic dispersions could therefore be switched "ON" (i.e., $\mathrm{pH}>7=0.2 \mathrm{mg} \mathrm{mL}^{-1}$ ) and "OFF" (i.e., $\mathrm{pH}<4=0.05 \mathrm{mg} \mathrm{mL}^{-1}$ ) by changing the $\mathrm{pH}$ (see Supporting Information). In the context of biomolecular applications, it would be of interest to develop a switchable surfactant that could be triggered at constant and physiological conditions. To this end, Fmoc-W was converted into an enzymatically switchable surfactant by capping the carboxylic acid group of the surfactant with enzyme recognition motifs, leucine (L) and glycine (G) methyl esters (OMe) (see Supporting Information). It was postulated that the inactive peptide precursors would bind to the CNT surface via $\pi-\pi$ interactions but could not disperse the nanotubes since it carried no overall charge. Upon enzymatic hydrolysis of the amide bond, the nonaromatic L-OMe fragment is expected to diffuse away from the surface (Figure 3a), leaving anionic Fmoc-W bound to the nanotubes, resulting in the dispersion being switched ON. Two complementary enzymes were selected to test this concept. Thermolysin is known to hydrolyze peptide bonds on the amino side of hydrophobic residues such as $L$ (and not $G$ ), while chymotrypsin hydrolyzes the carboxylic side of aromatic amino acids such as $\mathrm{W} \cdot{ }^{[23]} \mathrm{As}$ expected, the ability of Fmoc-W-G/L-OMe precursors to disperse CNTs was limited due to the bound peptide residing in the uncharged state (Figure 3b). The presence of enzyme solution $\left(0.1 \mathrm{mg} \mathrm{mL}^{-1}\right)$ in the absence of the peptide gave rise to a degree of protein-induced dispersion by enzyme adsorption $\left(0.21 \pm 0.01 \mathrm{mg} \mathrm{mL}^{-1}\right)$. To avoid enzyme adsorption onto the CNTs, the enzymes were covalently immobilized onto aminofunctionalized glass microbeads (MBs, $30-50 \mu \mathrm{m}$ in diameter) using glutaraldehyde crosslinking (see Supporting Information). ${ }^{[24]}$ The total protein crosslinked on the surface of the immobilized enzyme MBs was $408 \pm 54.3 \mu \mathrm{g}$ chymotrypsin and $328 \pm 43.2 \mu \mathrm{g}$ thermolysin per mg of MBs (see Supporting Information). Upon exposure of immobilized enzyme MBs to CNTs in the presence of the appropriate peptide precursor, the same level of dispersion could be obtained when enzyme selectivity matched the peptide precursor.

In summary, we have demonstrated the ability of Fmoc amino acids to disperse CNTs and interpreted the experimental results by quantum mechanical modeling. Furthermore, we have introduced enzymatically activated CNT surfactants that create homogeneous aqueous nanotube dispersions on-demand under constant and physiological conditions. We believe that the switchable, versatile and low cost surfactants developed here provide a step forward for applications where an interface between biological systems and carbon nanomaterials is required.

\section{Keywords:}

carbon nanotubes · dispersions · enzymes · modeling · peptides

[1] Y. Lin, S. Taylor, H. Li, K. Fernando, L. Qu, W. Wang, L. Gu, B. Zhou, Y. Sun, J. Mater. Chem. 2004, 14, 527.

[2] H. Dai, Acc. Chem. Res. 2002, 35, 1035.

[3] V. Moore, M. Strano, E. Haroz, R. Hauge, J. R. Smalley, J. Schmidt, Y. Talmon, Nano Lett. 2003, 3, 1379.

[4] S. Gotovac, H. Honda, Y. Hattori, K. Takahashi, H. Kanoh, K. Kaneko, Nano Lett. 2007, 7, 583.

[5] C. Ehli, D. M. Guldi, M. Á. Herranz, N. Martín, S. Campidelli, M. Prato, J. Mater. Chem. 2008, 18, 1498.

[6] S. Wang, E. Humphreys, S. Chung, D. Delduco, S. Lustig, H. Wang, K. Parker, N. Rizzo, S. Subramoney, Y. Chiang, A. Jagota, Nat. Mater. 2003, 2, 196.

[7] M. Pender, L. Sowards, J. Hartgerink, M. Stone, R. Naik, Nano Lett. 2006, 6, 40.

[8] P. Petrov, F. Stassin, C. Pagnoulle, R. Jerome, Chem. Commun. 2003, 2904.

[9] N. Nakashima, Sci. Technol. Adv. Mater. 2006, 7, 609.

[10] M. Numata, M. Asai, K. Kaneko, T. Hasegawa, N. Fujita, Y. Kitada, K. Sakurai, S. Shinkai, Chem. Lett. 2004, 33, 232.

[11] S. S. Karajanagi, H. Yang, P. Asuri, E. Sellitto, J. S. Dordick, R. S. Kane, Langmuir 2006, 22, 1392.

[12] A. M. Smith, R. J. Williams, C. Tang, P. Coppo, R. F. Collins, M. L. Turner, A. Saiani, R. V. Ulijn, Adv. Mater. 2008, 20, 37.

[13] Z. Yhang, H. Gu, Z. D. Fu, P. Gao, J. Lan, B. Xu, Adv. Mater. 2004, 16, 1440.

[14] C. J. Duxbury, I. Hilker, S. de Wildeman, A. Heise, Angew. Chemie 2007, 119, 8604.

[15] H. W. Gu, P. L. Ho, K. W. T. Tsang, L. Wang, B. Xu, J. Am. Chem. Soc. 2003, 125, 15702.

[16] A. Laromaine, L. Koh, M. Murugesan, R. V. Ulijn, M. M. Stevens, J. Am. Chem. Soc. 2007, 129, 4156.

[17] C. Singh, M. Shaffer, I. Kinloch, A. H. Windle, Phys. B. Cond. Matt. 2002, 323, 339.

[18] P. Jurecka, J. Sponer, J. Cerny, P. Hobza, Phys. Chem. Chem. Phys. 2006, 8, 1985.

[19] J. P. McNamara, I. H. Hillier, Phys. Chem. Chem. Phys. 2007, 9, 2362.

[20] J. P. McNamara, R. Sharma, M. A. Vincent, I. H. Hillier, C. A. Morgado, Phys. Chem. Chem. Phys. 2008, 10, 128.

[21] Y. Zhang, Y. Tan, H. Stormer, P. Kim, Nature 2005, 438, 201.

[22] T. Roman, W. A. Dino, H. Nakanishi, H. Kasai, Eur. Phys. J. D 2006, 38, 117.

[23] G Moss,, Nomenclature and classification of enzymes by the reactions they catalyze, http://www.chem.qmul.ac.uk/iubmb/ enzyme/EC3/4/21/1.html, last accessed August 2008.

[24] A. Basso, L. De Martin, C. Ebert, L. Gardossi, P. Linda, F. Sibilla, Tetrahedron Lett. 2003, 44, 5889.

Received: August 12, 2008 